\title{
EDITORIAL
}

\section{La libertad religiosa en España. ¿Hacia un nuevo mo-} delo normativo?'

\section{Consejo de Redacción}

Palabras clave: Libertad religiosa, laicidad integral, modelos de laicidad, modelo normativo, islamismo, símbolos religiosos.

Key words: religious freedom, comprehensive secularism, secularism models, legal model, Islam, religious symbols.

Mots clés: Liberté religieuse, laïcité intégrale, modèles de laïcité, modèle normatif, islamisme, symboles religieux.

El gobierno español ha anunciado el propósito de presentar al Parlamento antes de que termine el año 2009 un proyecto de ley orgánica sobre libertad religiosa que, después de casi treinta años, sustituya a la vigente. En este momento no conocemos el anteproyecto de Ley, pero con todo nos parece una buena ocasión para tratar sobre el ejercicio de la libertad religiosa en España a la luz de lo sucedido en nuestro país en el último tercio de siglo²

Es sabido que el derecho de libertad religiosa es un derecho humano, y como tal reconocido y tutelado, aunque de formas diversas, en el contexto occidental.

' Fecha del cierre del editorial: 8 de octubre de 2009

${ }^{2}$ El consejo de redacción se reunió para tratar este tema en el "Seminario permanente de Fomento Social" el día 21 de mayo y en reuniones sucesivas los días 16 de junio, 16 de septiembre y 2 octubre de 2009, con participación en algún caso de personas y especialistas externos al Consejo. 
Por eso nos parece muy importante comenzar definiendo los grandes modelos existentes en nuestro entorno cultural respecto al modo en que los Estados se posicionan ante el hecho religioso. Buscamos, por una parte, ganar en perspectivas y horizontes que nos aporten luz en relación con el ejercicio de este derecho $y$, por otra, poder contextualizar y comprender mejor las opciones adoptadas por los constituyentes españoles en esta materia. La regulación constitucional de este derecho fundamental será analizada a continuación, pues constituye el gran marco político-jurídico en el que debe desarrollarse este derecho en nuestro país. Nos detendremos brevemente en el desarrollo que de este derecho realizó la Ley Orgánica de Libertad Religiosa de 1980 (LOLR, a partir de ahora). Seguidamente trataremos de identificar los cambios más relevantes, que han tenido lugar en la sociedad española desde 1978 hasta nuestros días, en tanto que pueden tener significación e importancia en lo concerniente al ejercicio del derecho de libertad religiosa. Desde estos planteamientos pretendemos identificar en, primer lugar, los grandes retos y desafíos que en España presenta en la actualidad el reconocimiento y ejercicio de este derecho fundamental para, a continuación, pronunciarnos sobre los presupuestos ineludibles desde los que deben ser enfocados y abordados. Terminaremos proponiendo posibles aproximaciones o respuestas ante estos desafíos.

\section{Los grandes marcos jurídico-políticos de regulación de la libertad religiosa de nuestro entorno cultural}

El derecho fundamental a la libertad religiosa no se presenta igual en todas las sociedades de nuestro entorno occidental. Para enfocar con cierta claridad nuestra exposición nos hemos atrevido a establecer una tipología que esperamos sea útil para comprender la problemática actual española. Cada modelo parte de unos principios jurídicos, frecuentemente de rango constitucional, que configuran el ordenamiento del Estado en el que se protege y ejerce el derecho fundamental de libertad religiosa. Estos principios sirven para la regulación del hecho religioso y del control del contenido del ejercicio de la libertad religiosa, que debe ser congruente con aquéllos. Por último, los principios aportan elementos para la interpretación y aplicación de estas normas y para cubrir las posibles lagunas normativas. En definitiva, son los presupuestos a partir de los cuáles se desarrolla y aplica el sistema en el que se ejerce el derecho subjetivo de libertad religiosa. En general en nuestro entorno europeo y norteamericano podemos distinguir tres grandes modelos:

\section{I.I. Modelos confesionales o de identificación}

Es el propio de los países confesionales. Se da en el norte de Europa (casi todos los países escandinavos), en los Países Bajos y en el Reino Unido, países todos con mayorías protestantes, aunque también en Grecia, país éste de mayoría ortodoxa. La historia ha ido decantando un modelo de Estados frecuentemente confesionales con una religión de Estado y, por tanto, con un desarrollo muy débil de laicización del espacio público, en los que, por el contrario, la secularización cultural y social ha sido muy fuerte. De hecho en estos países la práctica y la adscripción confesional de sus ciudadanos son casi siempre muy bajas; sin embargo, paradójicamente, conservan en el espacio público las referencias religiosas confesionales. Las diferentes iglesias o confesiones tienen a veces carácter de Iglesias establecidas, pero frecuentemente sólo una de ellas es Iglesia nacional o estatal.

En todos estos países el elemento religioso ha sido importante, por motivos históricos diversos, para la identificación y caracterización del propio Estado. Nótese e caso de la Iglesia anglicana en el Reino Unido o la importancia que tuvo el poder civil del príncipe en las iglesias reformadas.

\subsection{Modelos laicos o abstencionistas}

Son modelos anteriores a la aparición del Estado social. Surgieron en momentos históricos, a veces revolucionarios y antirreligiosos. Lo importante era afirmar la libertad de conciencia y la libertad religiosa. Por ello son respetuosos y protectores del derecho de libertad religiosa, pero no son modelos que favorezcan el desarrollo de ese derecho, en la clave posterior del Estado social. Este modelo, según las circunstancias sociales en el que surgió ha derivado, a su vez, en dos submodelos:

\section{I.2.I. Modelo laico excluyente}

Es propio de países con un Estado laico con laicidad excluyente o negativa. En la Europa contemporánea, algunos Estados, singularmente Francia, han ido definiendo una forma de relaciones entre religiones y Estado basadas en el respeto y protección de la creencia y la práctica religiosa, pero con la absoluta neutralidad estatal ante las mismas y con exclusión expresa de cualquier reconocimiento estatal de las religiones en el espacio público. En Francia el proceso de secularización cultural y axiológica de la sociedad ha sido paralelo al proceso de laicización ju- 
rídica del espacio público. Francia no está sola en Europa, pues también Turquía es un Estado laico desde su fundación, pero evidentemente se trata de realidades muy distintas. Francia, un país de tradición cristiana, es una sociedad muy secularizada y con fuerte pluralismo religioso; Turquía, país de mayoría musulmana casi dominante, es una sociedad poco y desigualmente secularizada.

Los Estados que históricamente se mueven en este modelo pretendieron alejarse del monopolio que en la vida social, política y jurídica ejerció la confesión religiosa dominante. Para ello, tomaron distancia absoluta entre el Estado y el fenómeno religioso, que queda limitado, en el caso de Francia, prácticamente, al ámbito de la privacidad. Esta posición fue, en su día, históricamente innovadora y ha constituido un elemento configurador del propio Estado. Para el Estado francés, su carácter laico es uno de los principios de identidad del mismo, aunque es cierto que en los últimos tiempos están sonando voces cualificadas que abogan por una reconsideración de estos planteamientos ${ }^{3}$. Probablemente el crecimiento de grupos religiosos antes minoritarios y con tradiciones culturales diversas (los de origen musulmán), exija del Estado una política más activa ante el hecho religioso que vaya más allá del laissez faire, para que no se produzca el aislamiento de importantes sectores de la población.

\subsubsection{Modelo laico incluyente}

En Europa varios países responden a este modelo, pero es en los Estados Unidos donde se realiza más clara y ejemplarmente. La enmienda primera a la Constitución de los Estados Unidos prohibe que ninguna confesión tenga carácter estatal o reciba ayudas públicas pero, precisamente por no haber existido nunca ninguna confesión que gozase de carácter oficial, en Estados Unidos no existe tampoco dificultad ni rechazo para una notoria presencia pública de las diferentes confesiones religiosas en la vida pública, tanto de una de ellas como muy frecuentemente, de varias al mismo tiempo. La práctica de un ecumenismo religioso en el espacio público, con reiteradas referencias a los valores, los sím-

3 En los últimos años también en Francia se ha cuestionado la validez y viabilidad futura del modelo laicista francés, no sólo entre quienes oponen a una laicidad negativa, fría o simplemente laicista, una concepción de laicidad positiva (o cálida), sino entre quienes, sin cuestionar el núcleo de la validez de Estado laico, están dispuestos a reconocer un papel histórico y social de primer orden a las confesiones religiosas y en especial a la cristiana. Como muestra de ello se citan los sucesivos discursos del president religiosas y en especial a la cristiana. Como muestra de ello se citan los sucesivos discursos del presidente francés Nicolas Sarkozy en Roma y en Ryad (Arabia Saudita). Cf., nuestra edición del discurso de N. Fomento Social 63 (2008) 141-149. bolos y las creencias religiosas como patrimonio común de la nación americana es consustancial al espíritu de aquel país. En este modelo se parte claramente de la diferenciación entre Estado y sociedad, de tal forma que, aunque el Estado es laico, la sociedad no lo es ${ }^{4}$.

\section{Modelos cooperativos, antes concordatarios}

Estos modelos surgieron normalmente en países confesionales que, tras el reconocimiento de la libertad religiosa como derecho humano y el desarrollo del Estado social, reconocen la pluriconfesionalidad y, como Estados sociales que son, tratan de facilitar el desarrollo de los derechos fundamentales. Con frecuencia estos Estados partían de situaciones regidas por Concordatos con la Santa Sede. Este modelo está presente en Alemania, Italia, y también, como analizaremos en el apartado siguiente, en España. La cooperación se puede realizar de diversas formas y modos, otorgando estatutos jurídicos diferentes a las confesiones religiosas: en Alemania se les otorga el carácter de corporaciones de derecho público y en España son asociaciones de relevancia constitucional.

En la práctica social y política de estos países sigue habiendo una cierta identificación de la religión histórica y socialmente mayoritaria como religión nacional lo que se traduce frecuentemente en prácticas simbólicas religiosas confesionales en el espacio público ${ }^{5}$. En estos países a veces se ha producido una laicización jurídica débil en el espacio público, con diferentes niveles de secularización cultural, aunque en general la confesión mayoritaria sigue siendo un actor importante en el mismo, especialmente en aspectos culturales, sociales y axiológicos, que son apoyados por una fuerte red de instituciones.

Esta breve panorámica nos permite extraer una primera conclusión. La regulación e implantación del hecho religioso responde, sobre todo y ante todo, a procesos

${ }^{4}$ Las siguientes palabras del presidente Bill Clinton eran muy significativas al respecto: "(...) Una de las cosas de las que me siento más orgulloso como Presidente de los Estados Unidos ha sido la de sancionar con la firma la Ley para la Restauración de la Libertad Religiosa de 1993 (...) Nuestros Fundadores comprendieron que la libertad religiosa era básicamente una moneda de dos lados. La Constitución protegía el libre ejercicio de la religión, pero prohibía el establecimiento de una religión. Ese equilibrio cuidadoso significa algo específicamente estadounidense. Ese es el genio de la Primera Enmienda. No nos hace un pais sin religion, como han sugerido algunos. Nos ha hecho el país más en la escuela secundaria James Madison de Virginia.

${ }^{5}$ Como veremos la utilización de los símbolos en el espacio público es uno de los temas que están en debate en el ejercicio de la libertad religiosa en España. 
históricos y sociales diversos, que fraguan en diferentes sistemas o modelos normativos. Por eso, en los países democráticos más avanzados del mundo, existen modelos muy plurales, desde los estrictamente confesionales (Reino Unido) hasta los más laicistas (Francia). Es significativo que en estos dos modelos la posición que el Estado adopta ante el hecho religioso es, por motivos diversos, un importante elemento identitario para el propio Estado. Existen situaciones intermedias, cuya respuesta ante el hecho religioso viene motivada por las características que configuran al propio Estado, partiendo siempre del reconocimiento de la pluriconfesionalidad como hecho derivado del ejercicio de la libertad religiosa. De esta forma, en sociedades y Estados con tendencias más orientadas al Estado liberal clásico, nos encontramos con modelos laicos como es el caso del estadounidense. En cambio, en Estado sociales como el alemán, italiano y español, nos encontramos con modelos de cooperación con las confesiones con el objeto de hacer más pleno el derecho fundamental de libertad religiosa.

\section{La regulación de la libertad religiosa en España}

\section{I. Antecedentes}

En el siglo XIX existió tanto un régimen de religión oficial de Estado confesional con la Constitución liberal de 1812, como un régimen de tolerancia de cultos, con libertad de ejercicio privado de los mismos (como establecía la Constitución de 1876).

La Constitución republicana de 1931 estableció que el Estado español no tiene religión oficial (art. 3); que el Estado, las regiones, las provincias y los municipios no mantendrán, favorecerán ni auxiliarán económicamente a las Iglesias, asociaciones e Instituciones Religiosas (art. 26); y que la libertad de conciencia y el derecho de profesar y practicar libremente cualquier religión quedan garantizados en el territorio español, salvo el respeto debido a las exigencias de la moral pública (art. 27).

Las Leyes fundamentales de la dictadura franquista volvieron a establecer un Estado confesional. Más tarde, tras el Concilio Vaticano II, la nueva doctrina católica influyó, más formal que realmente, sobre la legislación franquista. En la declaración conciliar Dignitatis humanae sobre la libertad religiosa $(1965)^{6}$ se declaraba

${ }^{6}$ Cfr. J. RUIZ-GIMÉnez (1968) El Concilio Vaticano Il y los derechos del hombre, Madrid, Cuadernos para que la libertad religiosa se funda esencialmente en la dignidad humana de la persona, por lo que es un derecho de todos. Éste consiste en la inmunidad que debe proteger a todas las personas para que nadie, ni individual, ni colectiva ni institucionalmente, "obligue a nadie a obrar contra su conciencia ni se le impida actuar conforme a ella en privado y en público". " El Concilio instaba asimismo al reconocimiento jurídico de la libertad religiosa por parte de la sociedad, de manera que ésta se convirtiese en un derecho civil. El Concilio, sin embargo, declaraba algo más sobre el fundamento de la libertad religiosa:

Todos los hombres, por ser personas, es decir, dotados de razón y de voluntad libre y, por tanto, enaltecidos con una responsabilidad personal, son impulsados por su propia nalu a leza a buscar la verdad, y además tienen la obligación moral de buscarla sobre todo en lo que se refiere a la religion. Están obligados, además, a adherirse la verdad conocida y a ordenar toda su vida según las exigencias de la verdad. Pero los hombres no pueden satisfacer esta obligación de forma adecuada a su propia naturaleza si no gozan de libertad psicológica al mismo tiempo que de inmunidad de coacción externa. (...) el derecho a la libertad religiosa no se funda en la disposición subjetiva de la persona, sino en su misma naturaleza. Por lo cual el derecho a esta inmunidad permanece también en aquellos que no cumplen la obligación de buscar la verdad y adherirse a ella; y no puede impedirse su ejercicio con tal de que se respete el justo orden público. ${ }^{8}$

En 1967, el Estado español, en virtud de su carácter confesional, se vio "obligado"9 a introducir en su ordenamiento interno a través de la Ley 4/1967 el principio conciliar de libertad religiosa. ${ }^{10}$ Esta ley venía a establecer un sistema de libertad de cultos en régimen de tolerancia más parecido al de 1876, que seguía siendo interpretada en un contexto de Estado autoritario y confesional, sin un sistema constitucional de libertades públicas y derechos reconocidos ni un sistema de garantías.

el Diálogo; y J. Ruz-Giménez (1985) El camino hacia la democracia. Escritos en "Cuadernos para el Diálogo", Madrid, Centro de Estudios Constitucionales [edición del INSTITUTO FE Y SECULARIDAD].

7 Concilo Vaticano II (1965) Declaración Dignitatis humanae, n.2.

${ }^{8} \mathrm{lbid}$

'El político democristiano español Joaquín Ruiz-Giménez Cortés, recientemente fallecido (27-VIII-2009), que había sido auditor conciliar, ha contado en repetidas ocasiones las dudas y resistencias que entre las autoridades del régimen franquista hubo antes de aceptar la doctrina conciliar sobre libertad religiosa español. Ciertamente la libertad religiosa tal como era entendida por el fadicalmente el principio de confesionalidad del Estado español.

10 Para un análisis pormenorizado sobre todos estos aspectos, principalmente en su vertiente teológica puede verse el reciente y amplio estudio de J. L. MARTínEz (2009) Libertad religiosa y dignidad humana. Claves católicas de una gran conexión, Madrid, Paulinas, 370 pp. 


\subsection{La Constitución de 1978: el derecho fundamental de libertad religiosa}

La Constitución de 1978 dio un gran paso en relación con la historia constitucional española anterior al introducir el principio de libertad religiosa sin ninguna limitación. En el artículo 16 de la Constitución española se han sentado las bases fundamentales del tratamiento jurídico del factor religioso, al garantizar en su número primero la libertad religiosa, en su vertiente individual y colectiva ${ }^{11}$, y en su número tercero ${ }^{12}$ la no estatalidad de ninguna confesión y la cooperación del Estado con las confesiones religiosas, entre ellas la Iglesia católica. Para la correcta interpretación de estos principios constitucionales que informan el derecho eclesiástico del Estado, es preciso buscar su correspondencia con los valores y principios generales del ordenamiento, que vertebran el derecho y constituyen un sustrato esencial, del cual nacen, como derivaciones específicas, los principios y valores de cada rama jurídica.

Hemos de partir por tanto de los valores superiores de la libertad y de la igualdad, como forma de concreción en lo jurídico de la dignidad de la persona humana que, en virtud del artículo 10 de la Constitución, constituye, junto con los derechos inviolables que le son inherentes, uno de los fundamentos del orden político y de la paz social. El principio de libertad lleva consigo el reconocimiento de la libertad ideológica, religiosa y de culto ( art $^{\circ} 16.1$ de la Constitución). Esta libertad ideológica, religiosa y de culto debe ser garantizada no sólo en su titularidad, sino también en su ejercicio concreto, pues el artículo 9.2 de la Constitución dispone que corresponde a los poderes públicos promover las condiciones para que la libertad y la igualdad del individuo y de los grupos en que se integran sean reales y efectivas, removiendo los obstáculos que impidan o dificulten su plenitud. A su vez, el principio de igualdad comporta el reconocimiento del principio de no confesionalidad del Estado o de laicidad (art ${ }^{\circ} 16.3$ de la Constitución), en cuanto que el Estado no puede hacer suya ninguna confesión, pues de hacerlo estaría tratando desigualmente a los sujetos que creen en una confesión concreta con respecto a los que creen en otras 0 , simplemente, no creen. Es, precisamente, el reconocimiento constitucional del derecho fundamental de libertad religiosa y del principio de laicidad lo que lleva a la necesidad de reconocer el principio -

"El artículo 16.1 establece: Se garantiza la libertad ideológica, religiosa y de culto de los individuos y las comunidades sin más limitación, en sus manifestaciones, que la necesaria para el mantenimiento del orden público por la ley.

${ }^{12}$ El artículo 16.3 de la Constitución dispone lo siguiente: Ninguna confesión tendrá carácter estatal. Los poderes públicos tendrán en cuenta las creencias religiosas de la sociedad española y mantendrán las consiguientes relaciones de cooperación con la Iglesia Católica y las demás confesiones. de cooperación con las confesiones religiosas. ${ }^{13} \mathrm{Al}$ ser el Estado en esta materia incompetente por el principio de laicidad, incluso constitucionalmente, viene obligado a buscar la cooperación con las confesiones religiosas, para que éstas sean las que, con la colaboración del Estado, puedan llegar a hacer posible la realización práctica del derecho fundamental de libertad religiosa de los ciudadanos. La sociología de las religiones nos demuestra que este derecho fundamental se realiza, en la práctica, a través de la pertenencia o la participación en una confesión religiosa, lo que hace inevitable la colaboración del Estado con las confesiones religiosas para hacer posible, en última instancia, tal derecho.

\subsection{La Ley Orgánica de Libertad Religiosa de 1980}

Es esta una ley "principialista", que forma parte del bloque de constitucionalidad. Se trata de una norma de carácter muy general que desarrolla lo que podríamos denominar principios esenciales con respecto al derecho fundamental de libertad religiosa. En el artículo 1 se declara que el Estado garantiza el derecho fundamental de libertad religiosa de acuerdo con lo establecido en esa ley (art ${ }^{\circ} 1.1$ ) que las creencias religiosas no constituirán motivo de desigualdad o discriminación ante la ley (art ${ }^{\circ} 1.2$ ), y que ninguna confesión tendrá carácter estatal (art ${ }^{\circ}$ 1.3).

A continuación la LOLR regula el alcance y contenido del derecho (art ${ }^{\circ} 2$ ) y los límites de su ejercicio ( $\operatorname{art}^{\circ} 3.1$ ), para concretarse después el ámbito de protección de la ley, que excluye las actividades, finalidades y Entidades relacionadas con el estudio y experimentación de los fenómenos psíquicos o parapsicológicos o la difusión de valores humanísticos o espirituales u otros fines análogos ajenos a lo religioso ( $\operatorname{art}^{\circ}$ 3.2). Más adelante se regula el reconocimiento de la personalidad jurídica civil de las entidades religiosas tras su inscripción en el correspondiente registro ( $\operatorname{art}^{\circ}$ 5) y la autonomía organizativa de las mismas, así como su capacidad de crear y fomentar, asociaciones, fundaciones e instituciones (art ${ }^{\circ}$ 6.2) Asimismo se regula la posibilidad de que el Estado establezca acuerdos o convenios de cooperación con confesiones y comunidades religiosas inscritas que, por su ámbito o número de creyentes, hayan alcanzado notorio arraigo en España (art 7 ).

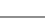

${ }^{13}$ Cf. J. JIMÉNEZ EsCOBAR (2002) Los beneficios fiscales de la Iglesia católica. Negociación, fundamento y alcance, Bilbao-Córdoba, Desclée de Brouwer - ETEA, pp. 179-191. 


\section{Los cambios de los últimos treinta años en el ejercicio de la libertad religiosa}

\section{I. De un modelo normativo confesional a otro pluriconfesional}

Nos referimos tan sólo a dos de los acontecimientos más significativos que ponen de manifiesto el tránsito a este modelo normativo. El primero de ellos es la firma en 1992 de los Acuerdos de cooperación con otras confesiones distintas de la católica $^{14}$. Estos acuerdos sirvieron como marco para convenios de distinta naturaleza sobre enseñanza religiosa, obligaciones fiscales, asistencia jurídica en el ejército, etc. Es una consecuencia del principio constitucional de cooperación y supone transitar por la senda "pacticia" en la regulación de las cuestiones que afectan al derecho fundamental de libertad religiosa con confesiones de notorio arraigo. De esta forma, la Ley Orgánica de Libertad Religiosa se constituye en una ley marco para todas las confesiones, siendo regulados aspectos concreto del ejercicio de ese derecho a través de las mencionadas normas "pacticias" (acuerdos con las diferentes confesiones o comunidades, incluida la católica). Esto responde a un esquema lógico, en el que al Estado le corresponde fijar el marco general, a través del bloque de constitucionalidad (Constitución y ley orgánica) y dado el carácter aconfesional del mismo, con la consiguiente incompetencia en materia religiosa, colabora con las confesiones religiosas en las medidas concretas que posibilitan el ejercicio y desarrollo pleno del derecho.

El segundo de los acontecimientos se ha producido en la primera legislatura de gobierno de Rodríguez Zapatero, al crearse por acuerdo del consejo de ministros de 15 de octubre de 2004 la Fundación Pluralismo y Convivencia, de iniciativa gubernamental, para apoyar económicamente a las distintas confesiones religiosas minoritarias y distribuir ayudas estatales a las mismas. Se trataría de facilitar el desarrollo del derecho fundamental de libertad religiosa para estas confesiones minoritarias.

\subsection{La articulación política y legislativa del pluralismo religioso y axiológico}

Este aspecto tiene incidencia sobre el ejercicio de la libertad religiosa. En él intervienen tres tipos de factores: sociológicos (el cambio de valores en la modernidad tar-

${ }^{14}$ Leyes $24 / 92,25 / 92$ y $26 / 92$ de 10-XI-1992, referentes a las comunidades evangélica, israelita y musulmana. día), ideológicos (el papel de la religión en el debate público) y de estrategia política (la necesidad de diferenciación entre los grandes partidos de izquierda y derecha).

Es un hecho que en España se ha producido, al igual que en el resto de Europa una mutación importante en los valores sociales predominantes: un fuerte individualismo, la prevalencia, en muchas ocasiones, de lo emotivo sobre lo racional, y como consecuencia de ambas cosas, de lo estético sobre lo ético. Por otra parte, está creciendo de facto una cultura predominantemente consumista, materialista e inmanentista, en la que valores espirituales y transcendentes quedan en muchas ocasiones desplazados de los proyectos vitales de los individuos o pierden bastante significación para los mismos. Todo esto ha contribuido a una creciente indiferencia hacia lo religioso en amplios sectores de la población española.

Jürgen Habermas ha puesto de manifiesto claramente la problemática del papel de la religión en el espacio público. Para este ilustre filósofo de nuestro tiempo debe existir un respeto positivo hacia las personas y modos de vida que claramente extraen su integridad y autenticidad de sus convicciones religiosas, un respeto que se convierte en una actitud dispuesta al aprendizaje. La religión debe abandonar la pretensión de monopolizar la interpretación, pero no debe renunciar a conectar de modo interno el éthos de la comunidad religiosa con el ordenamiento jurídico universalista y la moral social igualitaria. Esta expectación normativa del Estado liberal convergería así con los intereses propios de las comunidades religiosas, en la medida que éstas pueden así ejercer un influjo en la opinión pública y en la sociedad en su conjunto ${ }^{15}$, y reclama de los no creyentes que, si quieren dialogar con las comunidades religiosas, les reconozcan un estado epistémico no totalmente irracional. Este esfuerzo, que se exigiría en paralelo a los creyentes religiosos y a los no creyentes, sitúa al Estado y a su autoridad en una posición de imparcialidad ideológica que garantiza las mismas libertades éticas para todos los ciudadanos y es incompatible con la generalización política de una visión del mundo secularista de manera que los ciudadanos secularizados no deben negarles en principio a las visiones del mundo religiosas un potencial de verdad, ni negarles a sus conciudadanos creyentes el derecho a hacer aportaciones a los debates públicos. ${ }^{16}$

${ }^{15} \mathrm{Cfr}$. A. CoRtina (2001) Alianza y contrato. Políica, éfica y religión, Trotta, Madrid, especialmente

${ }^{15}$ Crr. A. CORT
pp. $133-182$.

${ }^{16}$ Habermas no sólo reclama el respeto a la intervención en la vida pública de los grupos religiosos, sino que va más allá, al considerar que para el Estado es conveniente y necesario este tipo de aportaciones: el Estado constitucional democrático exige al individuo un mayor compromiso en la medida esta ciudano funda en si mismo el Estado constitucional que, por eso mismo, pasa a ser un orden 
Adoptar posturas laicistas que en definitiva acaban siendo excluyentes por partir de una identificación irreal entre Estado y sociedad, es el resultado, no siempre pretendido, de una secularización extrema que descarrila. A veces esta exclusión llega a la ofensa o marginación en el espacio público de los grupos creyentes por el simple hecho de serlo. En efecto, el Estado es laico, pero la sociedad no lo es. Aquél no puede prescindir de parte de la sociedad en cuanto al papel, que como Estado democrático, le corresponde llevar a cabo en la articulación de los valores de la sociedad.

En relación con la estrategia política es ya un lugar común para la opinión pública que, sobre todo en los últimos veinte años, en Europa un gobierno de izquierdas para diferenciarse de un gobierno de derechas casi sólo puede cambiar aspectos culturales, pues existe un consenso básico compartido sobre el modelo socio-económico, aunque haya lógicos matices. Sin embargo, tanto por la emergencia de sujeto individual que cuestiona el paradigma de la modernidad ilustrada ${ }^{17}$, como por el agotamiento de las propuestas emancipatorias de la izquierda o las neoliberales de la derecha, los cambios en el terreno cultural (el religioso lo es estrictamente, aunque con un gran potencial simbólico) son especialmente propicios para escenificar el "clivage" entre izquierda y derecha. Desde la entrada de España en la Unión Europea, entonces CEE, las políiticas de gobiernos de ambas posiciones han puesto de manifiesto esta exclusividad cultural en la resolución de la diferencia política: los cambios vistos en clave de emancipación, de progreso.

socio-político autofundado. Esta carencia de referencia externa en la fundación de un orden político, por el contrario, va unida a un intenso y generoso interés no sólo en provecho propio, sino en el bien común. La carencia en que vive el ciudadano secular conleva un "mayor esfuerzo motivacional" imposible de imponer por vía legal, un esfuerzo unido a las virtudes polificas que son esenciales para la existencia de una democracia. El estatus de ciudadano, concluye Habermas, se halla inserto en una sociedad civil que se nutre de fuentes prepolíticas, es decir espontáneas. En muchas discusiones políiticas se juzga, de hecho, la interprefación correcta de los principios constifucionales, o dicho de otra forma se dialoga a partir de los principios de justicia que encuentran acomodo en el entramado, más denso, de las orientaciones de valor culturales. En opinion de Habermas, para poder recuperar, con algun esperanza de éxito, la solidaridad social en la vida del Estado constitucional, a este le conviene, por su propio interés, rratar de modo respeluoso a todas las fuentes culturales de las que se nutre la conciencia normativa y la solidaridad de los ciudadanos. CF. HABERMAS, J. Y RATZNGER, J (2005) "Diálogo entre la razón y la re en La Vanguardia, $1-V-2005$, pp. 26-29, cr., tambièn "Les fondements pré-politiques de IEtar démocrate". Esprii (2004) julio, así como HABERMAS, J. Y RATZNGER, J (2006), Dialéctica de la secularización: sobre la razón y la religión, Madrid, Encuentro. Se trató de un coloquio entre ambos

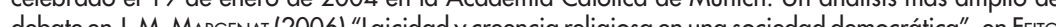
debale en J. M. MARGENAT (2006) "Laicidady creencia religiosa en una sociedad democrática", en Feito, Lydia (ed.) (2006) Encuentros y lensiones entre ideologlas, Menuid Asociación intisciplinar "Joś de Acosta" (Asinu), pp. 77-101.

17 Cfr. A. Touraine (2005) Un nuevo paradigma para el mundo de hoy, Barcelona, Paidós, pp. 129-179.
La necesidad de diferenciación ha llevado a que en nuestro país, en los últimos años, el partido en el gobierno haya esgrimido como elemento de diferenciación la bandera en el pretendido progreso en los derechos individuales. A ello se ha unido también la polémica suscitada con la asignatura educación para la ciudadanía que ha provocado importantes tensiones políticas y sociales. ${ }^{18}$

Estas importantes modificaciones legislativas afectan no sólo a intereses de grupos sociales, sino que se refieren a cuestiones fronterizas, no siempre suficientemente clarificadas o iluminadas desde el debate ético-filosófico; son cuestiones en las que los valores y las cosmovisiones se ven especialmente afectadas. Estas reformas legislativas vienen siendo aprobadas sin el deseable consenso de los dos partidos mayoritarios que representan a gran parte de la ciudadanía, por lo que la articulación de los valores de unos sectores y otros no queda suficientemente plasmada en la legislación promulgada. A ello se une cierta descalificación y desconsideración de los argumentos que desde los grupos religiosos se aportan al debate público, así como la incapacidad de los sectores más tradicionales de éstos en intervenir en este debate desde instancias y argumentaciones propias de la ciudadanía, con un lenguaje más secular y propio de la ética cívica, aunque esté en ultima instancia inspirado por la moral propia de la confesión religiosa. Estos hechos que acabamos de evocar nos ayudan a entender lo ocurrido en España en estos últimos dos años. En este contexto de confrontación es en el que se está planteando la necesidad de la reforma de la LOLR.

Todo esto se realiza en un ambiente social en el que gran parte de la población se inhibe de estos debates por la indiferencia religiosa. Las cuestiones quedan reducidas a posiciones que se sitúan en muchos casos de forma extrema. Muchos ciudadanos observan con perplejidad y desconcierto el fragor e intensidad de los intercambios de opiniones a través de los medios de comunicación social. Sólo la polarización extrema y la indeferencia permiten a veces ciertos cambios legales que en una sociedad más madura exigirían amplios consensos normativos entre los actores sociales más centrales. A veces parece que retorna con fuerza en la opinión pública la vieja contraposición entre clericales y anticlericales, aunque sea bajo otras formas que creíamos superadas por ser, en cualquier caso, más propias del siglo XIX que del nuestro ${ }^{19}$.

-

${ }_{18}$ Sobre el tema hicimos un comentario editorial, "Ciudadanía y educación: desafíos, incógnitas, posibilidades": Revista de Fomento Social 62 (2007) 151-177.

19 Un buen ejemplo de esta confrontación ha sido la reacción laicista de la Conferencia del PSOE celebrada en la primavera de 2008, tras la victoria electoral socialista, como respuesta, según autorizados analistas del área socialista, a la "movida" episcopal madrileña del 30 de diciembre de 2007 con ocasión de la jornada eclesial de la familia. 
Consideramos que el Estado no puede descalificar ni ignorar por principio las opciones y cosmovisiones que derivan de la sociedad y de los grupos que forman parte de ella, cuando estos se expresan a través de los canales propios de ex-

En estas espirales de reacciones no es fácil casi nunca señalar dónde empieza una provocación, ni cuál es la reacción. Intentemos, sin pretender dirimir quién empezo primero, recordar algunos hechos que se han sucedido en el tiempo. Ante algunas de las primeras iniciativas legislativas del PSOE tras la victoria electoral de 2004, hubo una fuerte reacción de algunos sectores de la jerarquía eclesiástica, incluso con movilizaciones en la calle, particularmente ante tres cambios legislativos: los que modificaban e código civil en cuanto a la concepción del matrimonio y en cuanto a su disolución, y la introducción de la formación escolar de educación para la ciudadanía.

El intento de un sector del PSOE de interpretar en sentido laicista esta nueva "educación para la ciudadanía" con el Manifiesto por la Laicidad, publicado en Málaga el 6 de diciembre de 2007, tuvo un significado limitado, pero no dejó de llamar la atención sobre una lucha de posiciones en el seno de propio partido, pues un grupo, el de los militantes cristianos del PSOE, respondió a dicho Manifiesto. Pueden verse en nuestra revista tanto el Manifiesto, como la reacción del arzobispo Sebastián Aguilar y la de los "Cristianos socialistas". Cfr. Revista de Fomento Social 60 (2006) 645-665.

En otoño de ese mismo 2007 se habían producido un conjunto de reacciones de algunos sectores católicos que culminaron en las jornadas de la familia que desde hace unos años se celebran coincidiendo con el último domingo después de Navidad, pero que el 30 de diciembre supusieron un verdadero exito de movilización mediática y de ocupación del espacio publico en el centro de Madrid. En aqued otoño el gobiemo había llevado a cabo una politica de "apaciguamiento bajo la dirección de la vicepresidenta M Teresa Fernández de la Vega, que asistió a las canonizaciones de ofoño de 2007 en Roma, coprolagonizada por el anterior nombramiento (2006) de Francisco Vázquez como embajador Canto cerca de la Santa Sede y las buenas relaciones con el nuncio en España, Manuel Montiro de Castro (nuncio entre 2000 y 200 ), este ullimo ha declarado recientemente que las relaciones entre la Santa Sede y el gobierno español eran buenas, lo que era corroborado favorablemente por el cardenal per elario de Estado, Tarsicio Bertone: no hay contencioso pendiente ninguno. La posición adoptada por el partido a principios de 2008 se interpreta por algunos analistas como la reacción legitima y a giosa en la precampaña y campaña electoral de invierno de 2008. Lo que, en cualquier caso parece quedar claro es que la equilibrada resolución Más laicidad para una mejor convivencia, aprobada por el PSOE en su conferencia de enero de 2008, solo se explica por un intento de pactar la posición

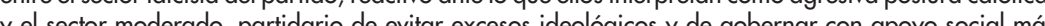
y el sector modrado, paridario de evilar excesos idélógicos y de gon

Como es sabido el asunto de la laicidad no estaba incluido en el programa electoral del PSOE que se había comenzado a preparar en octubre de 2007 . Un grupo, entre los que estaban alguno de los destacados juristas "eclesiasticistas" del PSOE, propone la revisión de los acuerdos del Estado con la Santa Sede. Sól en a a pre incluir el tema en la conferencia política. El Público de 1 1-|-2008 propone la reforma de la ley y País de 16-1-2008 propone la creación de un observatorio de la laicidad. En ese contexto inmediato, la corriente Izquierda socialista plantea 3 enmiendas: denuncia de los acuerdos, eliminación de las exenciones fiscales y revisión de la ley $7 / 1980$ de libertad religiosa. La propuesta no es aprobada las consigue votos suficientes para pasar al pleno que aprueba la redacción consensuada muy moderada a la que nos estamos refiriendo. presión de la ciudadanía: libertad de expresión, educación o manifestación. No parece en cambio pertinente que los actos de culto en espacios públicos puedan suponer, ni siquiera de forma indirecta, un cauce para la concreción, en aspectos político-legislativos, de la moral de cada confesión. Las confesiones, cuando saen a la arena pública, deben comportarse como ciudadanos y no como creyentes (está será su motivación última). Por ello, no es adecuado, en términos jurídicopolíticos, utilizar los cauces específicos y exclusivos de las opciones creyentes, las formas específicamente religiosas de manifestarse, que son amparadas y tuteladas por el Estado en la medida en que lo sean en el marco de sus finalidades concretas: la expresión y manifestación comunitarias, en cuanto creyentes, de su relación con la transcendencia.

La relación de esto con la libertad religiosa es clara e inequívoca. Por una parte excluir y descalificar a las opciones creyentes del debate público, a partir de sus opciones morales, supone desconocer que es inherente a toda confesión religiosa una moralidad que debe inspirar, animar y promover la opción de los creyentes, tanto en su vida personal como social. Si no se admite esto y la concepción de lo religioso se reduce específicamente a lo privado, ello supone, de facto, mutilar parte del ejercicio de la libertad religiosa que quedaría limitado a lo cultual y a la moral individual, no social. Nos parece que esta actitud no respetaría adecuadamente el derecho fundamental de libertad religiosa. A ello se añade que descalificar o prejuzgar negativamente las manifestaciones que puedan venir de ciertos ámbitos - grupos sociales que quieren intervenir como ciudadanos en la plaza pública, supondría atentar contra uno de los cimientos fundamentales del Estado español: su carácter democrático (España se constituye en un Estado social y democrático...).

Las actitudes que a priori descalifican a los argumentos procedentes de sectores confesionales, cuando éstos se realicen a través de los cauces adecuados y con un lenguaje comprensible para la mayoría de la ciudadanía, suponen que se resienta el Estado social (que pretende que los derechos se desarrollen de la forma más integral posible) y democrático (que postula la participación de la sociedad en la vida pública, más allá del derecho a participar a través del sufragio activo y pasivo).

\subsection{La irrupción de nuevos grupos religioso-culturales demográficamente} numerosos

La llegada masiva a nuestro país de población musulmana ha hecho que el Islam tenga una gran presencia social en nuestro país. Este hecho presenta varios desafíos a un Estado laico que pretende desarrollar el derecho fundamental de 
libertad religiosa de todos sus ciudadanos. Estos desafíos se presentan en varios órdenes: el marco jurídico-político en que se desarrolla la libertad religiosa en nuestro país, y ciertos límites existentes en el ejercicio de este derecho (Constitución, art ${ }^{\circ} 16.1$ y LOLR, $\operatorname{art}^{\circ} 3.1$ )

El Islam es una religión que configura todos los aspectos de la vida de sus fieles, en todas sus dimensiones. Lo personal y lo social aparecen iluminados con gran fuerza por la religión en los países de tradición musulmana de los que proceden muchos de los inmigrantes llegados a España. Religión, derecho y política aparecen en multitud de ocasiones, ligados por vínculos muy estrechos, y la libertad religiosa en dichos países no aparece, ni mucho menos, con un nivel de desarrollo simila al que existe en los países de Europa y América. Por lo que sabemos, la propia confesión musulmana no ha reflexionado con el nivel de profundidad que lo han hecho otras confesiones sobre al fundamento y alcance de la libertad religiosa.

Todo esto plantea algunos retos importantes para el Estado laico, pues los ciudadanos de religión musulmana procedentes de países donde imperan los caracteres político-jurídicos reseñados, deberán ejercer su derecho de la libertad religiosa en un entorno social, político y jurídico muy diferente. El Estado debe cooperar para que estos ciudadanos puedan desarrollar este derecho de tal forma que puedan percibir su integración real en la sociedad de acogida, de forma que no lleguen a aislarse en comunidades cerradas que vivan de espaldas a la sociedad. El desafío consiste en evitar cierta bipolarización entre sentirse creyente o ciudadano. El dilema entre ambas posiciones sería un falso dilema. El horizonte debe ser que se consideren ciudadanos creyentes, para lo que deben poder intervenir, desde sus planteamientos, en los debates públicos, debiendo facilitarse dichas intervenciones.

Por otro lado, la comparación entre el rol social de la mujer en las sociedades de tradición musulmana y el que se promueve y trata de potenciar en los países de acogida se ha planteado, en ocasiones, como una confrontación entre el respeto a los derechos humanos (uno de los límites al ejercicio de la libertad religiosa) y las prescripciones de la propia confesión. Entendemos que en este punto se deberá ser muy cuidadoso en las intervenciones por parte de los poderes públicos, para no dar pie a que se planteen falsos o aparentes dilemas a los que son muy dados los medios de comunicación social. No será fácil por ello adoptar decisiones de carácter general, las propias del derecho, sino que, probablemente habrá que afrontar estas cuestiones, si llegase a plantearse alguna contradicción desde planteamientos más poliédricos con medidas de muy diversa índole. En todo caso, no debemos ignorar la gravedad de ciertas situaciones extremas in- compatibles con nuestras tradiciones democráticas y nuestra concepción de los derechos humanos, especialmente en lo que se refiere a la posición social y cultural de la mujer y, por otra parte, sería conveniente promover que en los medios de comunicación social no se aborden estos temas con una simpleza que pueda desenfocar y confundir a importantes sectores de la población.

Finalmente, el riesgo real, no sólo imaginado, aun cuando haya también algo de esto último, del fundamentalismo latente en el "yihaddismo" islamista y sus posibles apoyos en partes muy minoritarias de la población musulmana supone también un importante reto. No es descabellado pensar que esto pueda generar en algunos cierta desconfianza respecto a los ciudadanos de confesión musulmana Si se vislumbrase cualquier tendencia en este sentido, debe ser rápidamente deslegitimada desde diversas instancias. La educación ciudadana, el conocimiento de las otras confesiones y la convivencia real, contribuirán a mitigar o atajar estas hipotéticas tendencias. Ello no impide que los cuerpos y fuerzas de seguridad del Estado deban identificar aquellas desviaciones en la confesionalidad que pueden llevar a que el orden público pueda verse transgredido, pues éste constituye un límite claro e inequívoco al ejercicio de este derecho.

Tampoco queremos excluir a priori de esta severa apreciación sobre el respeto de orden público las posibles desviaciones de ciertos sectores integristas que puedan parecer en el catolicismo o en otras confesiones.

La sociedad tiene que estar alerta ante la incompatibilidad entre el éthos democrático y ciertas prácticas regresivas o manipuladoras de la dignidad humana como aquellas a las que hemos aludido.

3.4. La concepción de las actividades benéficas y asistenciales de los grupos religiosos

Es frecuente que se produzca una reducción de lo religioso circunscribiéndolo a lo cultual o relacionado con las creencias que ha dificultado el acceso de instituciones benéficas, etc., creadas por confesiones religiosas, al correspondiente registro público. En la dimensión religiosa, sin embargo, el aspecto vinculado a la moral de la confesión tiene una relevancia muy significativa, tal y como reconocen hoy las ciencias de las religiones. La llamada a la acción desde determinados postulados morales que orientan la conducta, ha dado lugar en la mayoría de las confesiones religiosas a obras benéficas y asistenciales de los más diversos tipos. 
Hay actividades que en sí mismas, por su propia naturaleza, son inequívocamente religiosas (el culto por ejemplo, que sólo tiene sentido en el ámbito de la creencia religiosa). Sin embargo, hay otras actividades que no tienen constitutivamente ese carácter, pero que se pueden realizar con fines religiosos, ya que se trata de actividades muy adecuadas para desarrollar la dimensión moral propia a toda confesión: sanidad, educación o asistencia social, etc. El fin de la actividad lo pone el agente, por lo no se puede colegir que sólo existe motivación religiosa en las actividades claramente religiosas como son el culto o la difusión de las creencias.

Resulta muy clarificador a este respecto observar cómo en textos de naturaleza internacional, se considera a las actividades benéficas y asistenciales comprendidas dentro del concepto de lo religioso. Así, en la Declaración sobre la eliminación de todas las formas de intolerancia y discriminación fundadas en la religión o las convicciones, proclamada por la Asamblea General de las Naciones Unidas el 25 de noviembre de 1981, se encuentra una muestra muy clara del reconocimiento de la libertad de fundar y mantener instituciones benéfico-asistenciales como manifestación del derecho de libertad religiosa.

\section{Algunas orientaciones ante los cambios acaecidos}

4.I. Sobre la necesidad de una nueva ley de libertad religiosa y sus presupuestos

Consideramos que los cambios señalados no requieren, necesariamente, una nueva ley de libertad religiosa. Como hemos expuesto con anterioridad, la ley vigente es una ley de principios, que puede ser perfectamente interpretada, aplicada y desarrollada para afrontar los desafíos que el ejercicio del derecho plantea en España en estos momentos. En el apartado siguiente nos referiremos a algunas de las medidas que podrían adoptarse.

En cualquier caso, consideramos que toda posible modificación o sustitución de la LOLR, que forma parte del bloque de constitucionalidad, precisa realizarse desde unas bases muy sólidas $y$, necesariamente, consensuadas en lo político y en lo técnico-jurídico.

Sería recomendable también que, al igual que ocurre con cualquier proyecto legislativo, en su fase de difusión pública, se recabase la opinión de las confesiones religiosas, como suele hacerse con los proyectos legislativos que afectan a grupos concretos de la población.
Asimismo una materia tan importante y sensible como ésta debe regularse desde categorías jurídicas bien asentadas histórica y jurídicamente. Hay cuestiones en las que constituye un requerimiento indispensable la prudencia legislativa, procurando deambular por "tierra firme" y bien asentada. Hacemos mención a este aspecto porque, en ciertas ocasiones, ha circulado en ámbitos políticos o académicos el deseo de regular el derecho de libertad religiosa en el marco de una ley de creencias y convicciones. ${ }^{20}$ Este enfoque es minoritario en el ámbito académico y en nuestro contexto cultural, y supone una ruptura en la evolución y desarrollo de las instituciones jurídicas en nuestro país.

Sin entrar ahora en un análisis de técnica jurídica, los contenidos del derecho de libertad religiosa aparecen mucho más claros y nítidos que los que corresponden al ámbito de las convicciones, que presentan perfiles más difusos y ambiguos. Asimismo, el ejercicio de este derecho presenta unos caracteres muy diferentes, pues la dimensión grupal y comunitaria presenta una importancia y naturaleza que no concurre en el ejercicio de las convicciones no creyentes religiosas. Finalmente, la relación con la transcendencia, a través de los actos de culto, otorga también unas particularidades específicas a este derecho.

El hecho de que las creencias o convicciones puedan derivar de la libertad de conciencia no justifica que la regulación del derecho deba hacerse desde unos moldes y esquemas unitarios. Hay muchos derechos que derivan de la libertad, sin que por ello deban regularse y desarrollarse desde unos esquemas únicos. Menos comprensible aún resultaría que se pudiese entender que la libertad religiosa puede ser una derivación de la libertad ideológica, como, a veces, se ha postulado. Lo religioso no se circunscribe exclusivamente a lo ideológico, y considerar la religión como una manifestación más de las ideologías representaría una reducción del fenómeno religioso que no se ajusta a la realidad de los hechos. Por ello los constituyentes españoles distinguieron con nitidez en el artículo 16 entre la libertad ideológica y la religiosa.

\subsection{Algunas sugerencias para la actuación de los poderes públicos}

Transitar hacia un desarrollo integral del derecho de libertad religiosa requiere, por una parte, reconocer realmente que la dimensión moral inherente a cualquier confesión religiosa se traduce en la libertad de opinar, de educar y de intervenir, a partir de las propias convicciones, en la vida pública. Este tipo de intervencio-

${ }^{20}$ Cfr. J. LORENZO (2009) Vida Nueva, n 2.676, 26-IX a 2-X-2009, p 30. 
nes, a través de los cauces propios que tienen los ciudadanos para intervenir en el espacio público, se debe hacer desde los instrumentos específicamente previstos para este desarrollo: la libertad de expresión (en cualquier medio de comunicación), de manifestación o de educación (en cualquiera de sus ámbitos y niveles) La regulación de la forma de realizar la actividad corresponderá a esquemas de derecho general y no del derecho especial propio de la libertad religiosa.

La libertad de culto en el ámbito del espacio público, no así en los templos y otros lugares de culto, no debe ser utilizada para participar en ese tipo de debates, pues su objeto, en virtud del cual es tutelada por el ordenamiento, es otro.

Por otra parte, se precisa una comprensión de lo religioso que no se limite al culto - la divulgación de las creencias, puesto que la dimensión moral de lo religioso lleva al compromiso a través de obras de beneficencia, educación, asistencia social, médica u hospitalaria. En este caso, aunque la actividad no es en sí misma religiosa, la motivación del agente sí puede serlo y se desarrolla como una manifestación de su libertad religiosa. Por eso sería conveniente facilitar el acceso a registro de entidades religiosas a aquellas configuradas conforme a los esquemas propios de cada confesión (de Derecho Canónico por ejemplo) para poder realizar estas actividades. La libertad religiosa supone también respetar la forma en que se autoorganizan los miembros de esa confesión, y no someterlos a esquemas jurídicos diseñados por el Estado que no en todos los casos se acomodan a la confesión. Esto podría resolverse modificando o reinterpretando normativa de segundo nivel.

Orientar y colaborar activamente en un marco de pluriconfesionalidad es el reto principal con respecto a ciudadanos educados en tradiciones musulmanas en los que el ejercicio del derecho suele realizarse en marcos culturales uniformes. La colaboración activa, la educación a todos los ciudadanos, tanto los de ese credo como el resto de la población, y la promoción de la participación activa y pasiva de estos grupos en los espacios propios de la ciudadanía son esenciales. Esta colaboración posibilitará un desarrollo del derecho de libertad religiosa de estos ciudadanos en armonía con el entorno cultural y jurídico en que se desarrolla, en lugar de que se haga de espaldas al mismo.

Apoyar a los grupos religiosos minoritarios es una tarea prioritaria para el Estado social, que debe contribuir al desarrollo más integral posible de los derechos fundamentales de sus ciudadanos. Cuanto más pequeño y aislado es un grupo religioso, más dificultades puede encontrar para hacer posible el desarrollo del derecho de libertad religiosa de sus miembros. La Fundación Pluralismo y Convivencia creada a iniciativa gubernamental en 2004 probablemente pretenda caminar en esa senda. Pero nos parece que la posibilidad de convenios de colaboración debe extenderse también a las confesiones minoritarias como una forma más ordinaria de colaboración con las confesiones. Para ello, será preciso reinterpretar el alcance de notorio arraigo que contiene la LOLR o desarrollar su contenido en términos más generosos. Si esto no es suficiente, habría que plantearse analizar la conveniencia de modificar la Ley Orgánica en este punto.

En el tema de los símbolos religiosos todos, especialmente los poderes públicos, debemos actuar con prudencia. Decíamos al principio de este editorial que en los países con modelos cooperativos (antes concordatarios) seguían subsistiendo en el espacio público símbolos religiosos. Nos encontramos ante un tema delicado, pues los símbolos, como pocas cosas, conectan con las emociones y sentimientos, siendo un tema propicio para que con cierta facilidad se puedan producir posturas enconadas. Por otra parte, nos encontramos en un país que no ha sido especialmente habilidoso en lo que se refiere a la utilización de los símbolos propios; la identificación que hasta no hace mucho se ha realizado con ciertas ideologías políticas en los casos en los que las personas utilizaban de modos diversos la enseña nacional es una prueba de ello; la desazón que provoca en algunos que tengamos un himno carente de letra es otro caso. Finalmente, los símbolos religiosos traducen no sólo sentimientos identitarios con una confesión, sino que también son manifestaciones culturales y artísticas. Por todo ello, las posibles medidas que, en aras de la laicidad o aconfesionalidad, puedan tener lugar con respecto a los símbolos deberán partir de la prudencia, valorándose caso por caso el carácter o naturaleza que predominantemente tiene el símbolo (religioso, artístico, de identificación cultural) y cómo, en cada caso, se podría ver resentido el principio de aconfesionalidad. Hay que partir además del hecho de que, aunque en los edificios públicos la identificación con el Estado puede ser muy grande, en los espacios públicos como calles, plazas y otros, la identificación no tiene por qué ser tan intensa, en tanto que son también espacios sociales ${ }^{21}$.

Todas las medidas que acabamos de enunciar se enmarcarían en una concepción de un Estado con laicidad integral, a la que nos referimos en la conclusión.

${ }^{21}$ Parece muy acertada la Resolución de la Conferencia del PSOE de primavera de 2008, en la que se afirma, en relación con cuestiones como ésta, que las actuaciones deben realizarse de acuerdo sentir aeneral de la ciudadanía, pues no es propósito de los socialistas actuar por imperativo lega sino dirigir y acompañar esta evolución de la sociedad española. 


\section{Conclusión: hacia una laicidad integral}

Concluimos nuestro comentario proponiendo como marco para un posible nuevo modelo normativo una laicidad entendida integralmente, como propone nuestra Constitución. La laicidad que algunos llaman inclusiva, incluyente y, aun otros positiva ${ }^{22}$ también puede ser denominada laicidad integral. En primer lugar, la laicidad integral implica apertura a una antropología no reductora, una visión humanista integral en que la persona es considerada en todas sus necesidades expresivas o dimensiones, incluida la apertura a la trascendencia. ${ }^{23}$ Una laicidad integral es asimismo integradora de la pluralidad de confesiones realmente existente. Finalmente, la laicidad integral es integradora en cuanto reconoce también todas las dimensiones que tiene el derecho de libertad religiosa, tanto la cultual la de creencia, la axiológica o moral, aceptando su proyección en la vida socia (beneficencia, sanidad, educación), política (opinión ciudadana y de los grupos en que se integra) y cultural (presencia artística, literaria, etc.).

En suma, apostamos por una relectura positiva, creativa y abierta de nuestra laicidad constitucional que entendemos una laicidad integral. Desde la concepción cristiana que inspira nuestra revista creemos que esta laicidad abierta a la concepción trascendente de la persona es cívicamente válida y teológicamente legítima. Este humanismo integral de tradición personalista puede inspirar todas nuestras políticas de desarrollo del derecho fundamental a la libertad religiosa así como nuestra reflexión sobre una concepción humanista y solidaria de la libertad religiosa.

La versión inglesa del editorial está disponible en la página de la revista www.revistadefomentosocial.es. Se puede acceder tanto al texto castellano como a la versión en inglés desde la aparición del número.

22 Expresión usada en los últimos tiempos tanto por el Papa como por el presidente francés Sarkozy.

${ }^{23}$ En su última encíclica Caritas in veritate de 29-VI-2009, Benedicto XVI se ha referido a esta concepción humanista, citando las palabras de Pablo Vl en Populorum progressio (1967): No hay, pues, más que un humanismo verdadero que se abre al Absoluto en el reconocimiento de una vocación que da la idea verdadera de la vida humana. En ese humanismo integral se basa un desarrollo humano integral como el que propone el Papa (Caritas in veritate, nn. 17 y 19).

\section{ESTUDIOS}

Panorama de la integración centroamericana: Dinámica, intereses y actores

\section{Pedro Caldentey del Pozo ${ }^{2}$}

Palabras clave: Centroamérica, Integración centroamericana, SICA, Desarrollo regional. Key words: Central America, Central American Integration, SICA, Regional Development.

Mots clés: Amérique Centrale, Intégration centroamericaine, SICA, Développement régional.

\section{El renovado impulso de la integración centroamericana}

La integración centroamericana es hoy una realidad confusa pero vibrante. Frente a la sensación de crisis y de cambio de fundamentos que transmiten los procesos latinoamericanos de integración, el Sistema de la Integración Centroamericana $(\mathrm{SICA})^{3}$ exhibe un notable dinamismo del que son buenos síntomas la revisión y

' Una versión preliminar del presente texto aparecerá publicada en el libro: P. CALDENTEY y J. J. ROMERO (Editores), (2009), El SICA y la UE: un análisis de integración regional comparada (Capítulo 7). San Salvador, Fundación ETEA, UCA editores (en prensa).

2 El autor es doctor en Ciencias Económicas. Profesor de economía aplicada e investigador de la Fundación ETEA para el Desarrollo y la Cooperación. En la actualidad es Asesor principal del Fondo Fundación ETEA para el Desarrollo y la Cooperación. En la actualidad es

${ }^{3}$ Nota del Consejo de Redacción: el Sistema de la Integración Centroamericana (SICA), es el marco institucional de la Integración Regional de Centroamérica, creado por los Estados de Belice, Costa Rica, El Salvador, Guatemala, Honduras, Nicaragua y Panamá, aunque Belice y Panamá no participan en el proceso de formación de la Unión Aduanera (casi terminada). Además existen las categorías de Estados asociados y observadores. Es la integración más antigua de América Latina; con posterioridad 